\title{
Psychosocial sequelae of stoma surgery for inflammatory bowel disease in childhood
}

\author{
B LASK, J JENKINS, L NABARRO, AND I BOOTH \\ From the Department of Psychological Medicine and Department of Child Health, Hospital for Sick Children, \\ Great Ormond Street, London
}

SUMMARY Three matched groups of children with inflammatory bowel disease: (a) stoma group, (b) ileorectal anastomosis group and (c) no-surgery group were compared for psychosocial adjustment. No differences were found between the groups for psychological adjustment, selfesteem, or quality of life. It is concluded that providing children are well prepared and followed up carefully and sensitively, then stoma surgery should not be deferred for fear of adverse psychological consequences.

Stoma surgery in children with severe inflammatory bowel disease (IBD) may be delayed or avoided for fear of the potentially serious psychosocial consequences. This is an understandable reaction, given the mutilating nature of the surgery. On the other hand, failure to proceed to colectomy in colitis failing to respond to medical treatment has serious dangers, ranging from toxic megacolon and colonic perforation in severe fulminating colitis, to steroid induced growth failure, and malignancy in chronic active disease.

Little is known about the psychosocial sequelae of colectomy in childhood. In an uncontrolled study of 32 children with IBD, $75 \%$ felt their quality of life was improved after stoma surgery.' Details of their psychological adjustment and selfesteem are not available.

In adults who undergo stoma surgery, a variety of reactions have been documented. ${ }^{2}$ There are some differences between those having colostomies, compared with ileostomies, although this is understandable; in general, those having colostomies are older and are suffering from a relatively sudden onset of malignant disease. In contrast, ileostomists are generally younger, and have had their illness for much longer. Clearly there are exceptions.

Address for correspondence: Dr B Lask. Dept of Psychological Medicine. Hospital for Sick Children. Great Ormond Street, London WC1.

Received for publication 5 March 1987.
Allowing for these distinctions, people with colostomies tend to suffer from a sense of shame and repugnance, marked depression, social withdrawal, fear of spillage and odour, and anger and resentment towards the surgeon. ${ }^{3+}$ Ileostomists, in contrast, make a generally good adjustment, but many suffer fears of spillage and odour, and have social and sexual problems. ${ }^{67} \mathrm{~A}$ number of authors have pointed out that the attitude and helpfulness of those close to the patient are important determinants of outcome - for example, the spouse ${ }^{78}$ and the surgeon. ${ }^{9}$

A common observation of stoma patients is that psychological problems are often overlooked. They can pay an enormous price for their cure - physical discomfort, psychological, social and sexual problems. ${ }^{5}$ Given these concerns, the late Professor John Harries suggested we investigate the psychosocial sequelae of stoma surgery in inflammatory bowel disease in childhood.

\section{Methods}

\section{SUBJECTS}

Three groups of patients with inflammatory bowel disease were studied: those with a stoma, those with ileorectal anastomosis, and a third group treated entirely medicaily. The case notes of all children attending the Inflammatory Bowel Disease Clinic at the Hospital for Sick Children were examined and 12 
subjects with an intestinal stoma were identified as suitable for inclusion in the study on the basis of age at operation (between five and 14 years) and accessibility (living in England or Wales). Subjects within two years of stoma surgery were excluded.

This group of patients were matched as closely as possible for mean age at onset, duration of disease, sex distribution and mean age at follow up, with patients who had undergone an ileorectal anastomosis and also with a group of patients treated entirely medically (Table 1). In the two surgical groups the time between surgery and assessment were matched as closely as possible. A total of 38 patients were studied, 12 with a stoma, 13 with an ileorectal anastomosis and 13 in the non-surgical group. It was not possible to match the groups for severity of disease as this was a crucial factor in determining whether or not surgery, with or without a stoma, was necessary. There were equal numbers of patients with ulcerative colitis and Crohn's disease, but as would be expected, there was a preponderance of patients with ulcerative colitis in the stoma group and with Crohn's disease in the non-surgical group.

\section{SEMISTRUCTURED INTERVIEW}

Each patient received a semistructured interview, designed to elicit information on their psychosocial adjustment, knowledge of their body and disease, social life, school/work adjustment, attitudes to sex, marriage and parenting, work and life expectancy and their perceptions of the reactions of close relatives and friends.

\section{STANDARDISED TESTS}

As part of the psychosocial assessment, a series of standardised tests were used. Psychological adjustment was measured using the General Health Questionnaire $^{10}$ for patients over 16, and Rutter

Table 1 The sample

\begin{tabular}{lccc}
\hline Group & Stoma & Anastomosis & Nosurgery \\
\hline $\mathrm{n}$ & 12 & 13 & 13 \\
Male & 5 & 6 & 8 \\
Female & 7 & 7 & 5 \\
UC & 9 & 4 & 5 \\
Crohn's & 3 & 9 & 8 \\
Age at onset & $6-12$ & $1-13$ & $1-13$ \\
Mean & $7 \cdot 0$ & $7 \cdot 8$ & $7 \cdot 4$ \\
Duration of illness (yrs) & $3-25$ & $5-24$ & $1-20$ \\
Mean & $10 \cdot 8$ & $11 \cdot 0$ & $6 \cdot 9$ \\
Age range (yrs) & $9-29$ & $10-32$ & $10-26$ \\
Mean & $17 \cdot 8$ & $18 \cdot 9$ & $14 \cdot 2$ \\
Time from surgery to & $2-15$ & $2-22$ & \\
$\quad$ follow up (yrs) & & & \\
Mean & $7 \cdot 3$ & $7 \cdot 5$ & \\
& & & \\
\hline
\end{tabular}

No significant differences between the groups $(p<0 \cdot(05)$.
Parent and Teacher Questionnaires" for children, whilst selfesteem was measured using the Tennessee Self-Concept Scale'2 for over 16's and the Piers Harris Self-Concept Scale ${ }^{13}$ for under 16’s.

\section{STATISTICAI. ANAIYSIS}

Non-parametric tests were used for all analyses as the data were not normally distributed. Chi-Square, Van der Werden Test (non-parametric equivalent of the analysis of variance) and stepwise logistic regression procedures were used where appropriate and are quoted in the text. The acceptable level of significance was designated as $\mathrm{p}<0.05$.

\section{Results}

PSYCHOSOCIAL ADJUSTMENT

The findings are shown in Table 2. Using the cut off points given for the General Health Questionnaire and the Rutter Parents and Teachers Questionnaires, patients were grouped into satisfactory or unsatisfactory adjustment. No significant differences were found $\left(\chi^{2}=1 \cdot 63, \mathrm{NS}\right)$.

\section{SELFESTEEM}

The results are shown in Table 3 . There were no significant differences between groups on the children's level of selfesteem although the difference between the anastomosis and no surgery groups approaches significance (Van der Werden $\chi^{2}$ equivalent, $\chi^{2}=4 \cdot 82, p<0 \cdot(09)$ with children in the anastomosis group sharing higher selfesteem; nor were there any differences between groups for selfesteem of patients over 16 .

\section{QUALITY OF LIFE}

The results are shown in Table 4. The stoma and anastomosis groups were asked to rate their quality of life since surgery. Seven patients with stoma $(58 \%)$ and six patients with an anastomosis $(46 \%)$ said their life was better since their operation. Only one $(8 \%)$

Table 2 Psychosocial adjustment

\begin{tabular}{lccc}
\hline & Stoma & Anastomosis & Nosurgery \\
\hline Satisfactory & 10 & 10 & 8 \\
Unsatisfactory & 2 & 3 & 5 \\
\hline
\end{tabular}

Table 3 Mean scores on selfesteem questionnaires

\begin{tabular}{lrrr}
\hline & \multicolumn{1}{c}{ Stoma } & Anastomosis & Nosurgery \\
\hline Piers-Harris & $58 \cdot 6(n=5)$ & $62 \cdot 4(\mathrm{n}=5)$ & $54 \cdot 8(\mathrm{n}=9)$ \\
Tennessee & $343 \cdot 3(\mathrm{n}=7)$ & $355 \cdot 4(\mathrm{n}=8)$ & $335 \cdot 5(\mathrm{n}=4)$ \\
\hline
\end{tabular}


in the stoma group said it was worse compared with four $(30 \%)$ in the anastomosis group.

SCHOOL ATTENDANCE AND SEXUAL ADJUSTMENT Patients were asked about school attendance during childhood. The groups did not differ on how much school had been lost $\left(\chi^{2}=1 \cdot() 9\right.$, NS). Patients over 14 years of age were asked about present sexual behaviour. There were no differences between groups on whether or not patients were having sexual relationships $\left(\chi^{2}=0 \cdot 63, \mathrm{NS}\right)$.

PREDICTIVE FACTORS

A stepwise logistic regression procedure was used to examine whether any of the following variables predicted psychosocial adjustment: sex, disease type, age at onset of disease, duration of disease, understanding of body and disease, perceived reaction of close relatives and friends. None of these were predictive of psychosocial adjustment.

Similarly, within the stoma group none of these variables were associated with the patients adjustment: quality of preparation (Van der Werden $\chi^{2}$ equivalent, $=0.97$, NS), age at surgery (Van der Werden $\chi^{2}$ equivalent, $=0 \cdot 97$, NS), emergency or elective surgery $\left(\chi^{2}=() \cdot 3, \mathrm{NS}\right)$.

\section{Discussion}

To our knowledge this is the first controlled study of psychosocial adjustment to stoma surgery for childhood inflammatory bowel disease. Our findings must, however, be interpreted with some caution in view of the relatively small sample, the wide age range of the sample, the wide age range since stoma surgery, and the difficulties in matching the surgical groups with the non-surgical groups for severity of illness. Nonetheless it is encouraging that we found no evidence that stoma surgery is psychologically harmful, and certainly there were none of the devastating consequences that might have been predicted. We have reason to believe that the one child who was worse after stoma surgery would have been poorly adjusted whatever the course and treatment of illness given the severity of disturbance in his family over a period of several years.

It is surprising that we were unable to identify any prognostic factors, but again our sample may have

Table 4 Patient's rating of their quality of life since surgery

\begin{tabular}{lll}
\hline & Stoma & Anastomosis \\
\hline Better & 7 & 6 \\
Same & 4 & 3 \\
Worse & 1 & 4 \\
\hline
\end{tabular}

been too small to allow this. In our interviews with the patients, repeated mention was made of how important was the support or lack of it of their families. Also many expressed a wish for more comprehensive preparation, and in particular, the opportunity to have met preoperatively someone else with a stoma. A number of patients said they wished they could have had a stoma sooner.

Anxieties about leakage, noise, odour and what to tell others were common, as were concerns about social acceptability, fertility, and sexual desirability. There was no evidence that depression or social isolation commonly occurred. Most problems were overcome within 12 months of surgery. Of the six stoma patients over the age of 21 years, five had married or had experienced at least one steady relationship with a member of the opposite sex and of the three who were married two had children.

Our findings require cautious interpretation because of the relatively low numbers. We found no evidence, however, that stoma surgery in childhood is psychologically harmful and that no single factor is predictive of outcome. As yet there is no reason to believe that stoma surgery should be deferred for fear of adverse psychological sequelae. These generally positive findings are best illustrated by the following quote from a 25 year old man with a stoma since the age of 14. 'The first time my girlfriend and I were cuddling, she felt it and asked what it was; I told her, and she said "oh" and we just carried on!"

Acknowledgements to the late Professor John Harries for suggesting this project, The Ileostomy Association of Great Britain for their generous funding, Professor Mike Preece and Professor Keith Oakley for statistical advice and help, Professor John Walker-Smith for access to some of his patients, and to all the patients for kindly agreeing to be interviewed.

\section{References}

1 Hyams J, Grad R, Colodny A, Schuster S, Eraklis A. Course and prognosis. After colectomy and ileostomy for inflammatory bowel disease in childhood and adolescence. J Paediatr Surg 1982; 17: 400-5.

2 Briggs M, Plant J, Devlin H. Labelling the stimatised: the career of the colostomist. Ann $R$ Coll Surg Engl 1977; 59: 247-50.

3 Thomas C, Madden F, Jehu D. Psychosocial morbidity in the first three months following stoma surgery. J Psychosom Res 1984; 28: 251-7.

4 Morrow L. Psychological problems following ileostomy and colostomy. Mt Sinai J Med 1976; 43: 368-70.

5 McCawley A, Mannix H, McCarthy D. The psychological problems of ostomates. Connecticut Med 1975; 39: $151-5$. 
6 Druss R, O`Connor J, Stern L. Psychologic response to colectomy; 11: Adjustment to permanent colostomy. Arch Gen Psychiatry 1969; 20: 41927.

7 Brooke B. Sexual problems among married ilestomists. Gut 1977; 18: 673-7.

8 Dlin B. Emotional aspects of colostomy and ileostomy. Psychosomatics 1978; 19: 214-8.

9 Prudden J. Psychological problems following ilestomy and colostomy. Cancer 1971; 28: 236-8.
10 Goldberg D, Hillier V. A scaled version of the General Health Questionnaire. Psychol Med 1979; 9: 139-45.

11 Rutter M, Tizard J, Whitmore K. Education, health and behaviour. London: Longman, 1970.

12 Fitts WH. Tennessee Self-Concept Scale. Manual Tennessee Department of Mental Health Solf Concept Scale. Nashville, Tennessee: Tennessee Department of Mental Health. 1965.

13 Piers E. Harris D. Ages and other correlates of selfconcept in children. J Educat Psychol 1964; 55: 91-8. 